Crèdit Andorrà Chair of Markets,

Working Paper

MigIESE

Organizations and Humanism

WP no 692

May, 2007

University of Navarra

\title{
ON THE METHODOLOGY OF MANAGEMENT RESEARCH
}

\author{
Josep M. Rosanas
}




\title{
ON THE METHODOLOGY OF MANAGEMENT RESEARCH
}

\author{
Josep M. Rosanas*
}

\begin{abstract}
Epistemology, methodology or philosophy of science, i.e., the foundations and validity of knowledge, have never been very popular subjects as applied to management research. Lately, though, the need for better theories and the methodological discussion underlying the creation of such theories appears to be receiving more attention. In this paper, I will review some basic underlying issues in the area by taking a look at to some of the classical authors.

I will first analyze Hayek's view of methodological problems in economics and then apply his analysis to the development of management theory. Then, I'll elaborate on Elster's distinction between causal, functional and intentional explanations. Naiive methodological attitudes will be discussed in this context. I will use agency theory as an example of what should and should not be done. Finally, I'll examine the falsification criterion in management theory and discuss the role of mathematics in the development of theory.
\end{abstract}

\section{* Professor, Accounting and Control, IESE}

Keywords epistemology, philosophy of science, methodology, management theory, foundations of management. 


\section{ON THE METHODOLOGY OF MANAGEMENT RESEARCH}

\section{Introduction}

Epistemology, methodology and the philosophy of science, i.e., the foundations and validity of knowledge, have never been very popular subjects among management researchers. In the last forty years or so, some empirical research methods have come to be accepted (with or without strong methodological or epistemological foundations, as we will see) and management research has developed using these methods. Implicitly, in fact, they have become the standard of scientific acceptance and thus the implicit epistemology behind this research: anything empirical that uses accepted methods is considered scientific, whereas what is not empirical is considered highly doubtful. However, no philosopher of science would ever accept this view. The 'demarcation principle', to use Popper's well-known expression to separate the scientific from the unscientific (or the a-scientific), should be a substantially different one.

In some fields of management, this process has taken place more explicitly than in others. In accounting, for instance, there have been explicit discussions about whether research should be 'normative' (as it was by and large before the 1960s) or 'positive' (meaning essentially empirical) like it is for the most part now. 'Positive' is now considered to be 'scientific', while 'normative' has come to mean 'unscientific' (see Christenson, 1983, for a critical analysis of these issues). In other fields, the discussion may be less clear, but in practically all of them there is some concern about management research being 'too formal' and irrelevant for practice, and this has prompted some to doubt whether management can possibly be a science (e.g., Eccles and Nohria, 1992).

Yet the need for better theories and the methodological discussion underlying the creation of such theories has lately received increasing attention. Smith and Hitt (2005) recently edited a collection on the process of theory building with contributions from many of the best-known scholars, mostly in the fields of general management and organization behavior. In his posthumous article that will likely be his most influential contribution, Ghoshal (2005) raised the methodological issue as a crucial point in the development of 'bad management theories'. In her 2005 Presidential Address to the Academy of Management, Rousseau advocated for 'evidence-based management', i.e., "translating principles based on the best evidence into organizational practices" (Rousseau, 2006). 
Although her analysis is not focused on methodological issues, it is obvious that for something to be considered "evidence-based," there has to be a criterion of acceptance of what 'evidence' is, a methodological point that at least partly underlies Learmonth's commentary on Rousseau's Address. (Learmonth, 2006). Van de Ven and Johnson (2006) and McKelvey (2006) discuss the gap between theory and practice and acknowledge the methodological issues involved in getting knowledge from practice and research dating at least as far back as A ristotle.

In this paper, I will critically examine the basic epistemological issues in management research in an attempt to clarify some essential concepts. I will proceed as follows. First, I will discuss whether management can be considered a science and answer affirmatively by differentiating between 'science' and 'scientism'. Next, I will review Hayek's analysis of the essential methodological problems in economics and then apply his analysis to the development of management theory. Elaborate on Elster's distinction between causal, functional and intentional explanations to show that only intentional explanations are valid in the context of management research. Also attempt to show how naïve methodological attitudes can cause scientific developments to deviate from their proper ends. Agency theory, one of the most widely used models in management and economics, will provide an example of what should and should not be done. Finally, compare the falsification criterion with methodological problems in management theory and discuss the role of mathematics in the development of this theory.

\section{Science and Scientism in Management}

The first question is whether management can be considered a science. This question has been asked since the beginning of management theory about a century ago, and has been answered affirmatively by almost all the classical writers who have explicitly asked the question, and by many others who have asked it implicitly. For instance, Taylor made up the expression 'scientific management.' Somewhat more explicitly, Fayol's main purpose was to come up with a theory that could be taught to would-be managers. The question has been touched on in different degrees by many other classical authors writing on management. Mary Parker Follet uses excellent explicit arguments (Follet, 1927):

"Science has been defined as "knowledge gained by systematic observation, experiment and reasoning; knowledge coordinated, arranged and systematized.' Can we not accumulate in regard to human relations knowledge gained by systematic observation, experiment and reasoning? Can we not coordinate, arrange, and systematize that knowledge? I think we can" (p. 12 in the Matteson and Ivancevich edition).

Later on, Luther Gulick also answered the question affirmatively on slightly different grounds in a well-known article in the A cademy of Management whose title is categorical: Management is a Science (Gulick, 1965):

"When a field of knowledge has been defined, made 'public', pursued for some time, organized into an elaborate system of explicit primary and secondary theories, which have been or are being tested by logic and by the realities of the universe, so that past and current changes in the system can be explained and future changes predicted or produced, we call this ball of knowledge a science" (p. 10). 
Gulick believed that management was one of these balls of knowledge. However, he acknowledged that at different points in time, certain sciences had developed at different rates, and that management had been lagging behind other sciences for quite some time. But for him it was just a matter of time.

Neither Luther Gulick nor Mary Parker Follet went into an in-depth methodological analysis, but their arguments are very similar to those of Christenson, who does perform such analysis. By criticizing as too ambitious the objective of science, often assumed by many researchers of 'explaining' observed phenomena, he proposes a more modest objective of rationalizing a language (that of a particular science), which in fact means making it logically consistent, and applying this rationalized language to the description of empirical phenomena (Christenson, 1973, 1976, 1983). Einstein agrees: "The object of all science, whether natural science or psychology, is to coordinate our experiences and to bring them into a logical system" (1956).

In summary, management is (or, in the worst-case scenario, can become) a science. One has to be careful, though, not to fall into scientism, which, according to the Encyclopedia Britannica is "an exaggerated trust in the efficacy of the methods of natural science applied to all areas of investigation (as in philosophy, the social sciences and the humanities)."

Hayek was possibly one of the first economists to accuse the social sciences in general and economics in particular of 'scientism'. In his well-known book The Counter-Revolution of Science (1952), he strongly criticized economics when it imitated the methods of the natural sciences instead of the spirit of these sciences, and called this imitation a 'tyranny'. According to Hayek, this tyranny came from the fact that, during the first half of the $19^{\text {th }}$ century, the word 'science' was increasingly applied only to the natural sciences, while claiming at the same time a special righteousness and certainty. One might add that this righteousness and certainty were later proven wrong, thus making the scientistic attitude doubly wrong: because of the methods and the (false) certainties.

Hayek later made the subject one of the main points in his Nobel Lecture (1974):

"...failure of the economists to guide policy more successfully is closely connected with their propensity to imitate as closely as possible the procedures of the brilliantly successful physical sciences - an attempt which in our field may lead to outright error. It is an approach which has come to be described as the 'scientistic' attitude - an attitude which, as I defined it some thirty years ago, 'is decidedly unscientific in the true sense of the word, since it involves a mechanical and uncritical application of habits of thought to fields different from those in which they have been formed.' (...) Unlike the position that exists in the physical sciences, in economics and other disciplines that deal with essentially complex phenomena, the aspects of the events to be accounted for about which we can get quantitative data are necessarily limited and may not include the important ones." (1974)

Consequently, if we understand that 'science' means some body of knowledge that imitates the methods and type of results of the physical sciences in terms of clear-cut, causal explanations or perhaps the functional explanations of the biological sciences (see below), then management cannot be a science: 'intentions' (implicitly assumed away in these kinds of explanations) are a crucial part of interactions between people. Interestingly, it is this 'scientistic' approach that is (perhaps unknowingly and unwillingly) behind many criticisms of the notion that management is a science. Eccles and Nohria, who are among the modern critics of this possibility, argue (1992, p.175) against the applicability of scientific research to management and state that "the 
validity of formal ${ }^{1}$ research is judged by criteria that attempt to define good 'scientific' research, such as statistical significance, replicability and predictive power." Indeed, these may be the criteria to evaluate the methods of the natural sciences. But if, following Hayek's line of thought, the social sciences do not imitate the methods, but the spirit of the natural sciences, then one has to go beyond these criteria, as we shall see. If this is done, then management should be and already is a science, as Gulick stated in the title of his article. It therefore becomes crucial to establish the methodological bases of this science.

\section{Epistemological Problems in Economics}

Hayek's strong methodological critique in The Counter-Revolution of Science was directed in general at the social sciences and placed special emphasis on his negative opinion of the 'engineering point of view' exemplified by Saint-Simon. Though the spirit of the critique remained the same, Hayek applied it more specifically in his Nobel Lecture to macroeconomic problems, mainly to the statistical relationships between inflation, massive unemployment and aggregate output, i.e., to big aggregate variables for which it is often thought that statistics are enough. Hayek's main point is that this is not so. Following is a summary of Hayek's crucial points to show how he emphasizes in economics what I have just considered a distinct feature of management:

1) Data in the social sciences are subjective. Social sciences deal with the relations between people and things and between people, and different people react differently to identical stimuli at different times and under different circumstances. 'Opinions' held by observed individuals are 'facts' in the social sciences.

2) The purpose of the individual is crucial; and the unintended or undesigned consequences of the actions of many people are part of what has to be explained. Things are what acting people think they are: a 'tool' or an 'instrument' cannot be defined without mentioning purpose or intention.

3) In the social sciences, we have to deal with structures of essential complexity, i.e., structures whose characteristic properties can be exhibited only by models made up of relatively large numbers of variables. The properties usually attributed to competition (efficiency, etc.) will apply only if the number of agents is 'fairly large'. This happens to some extent in biology as well, but not so much in the physical sciences.

4) In the physical sciences, in some very complex problems affecting a high number of variables, the difficulties may be overcome by using data about probabilities instead of information about individual elements. These are phenomena of 'unorganized complexity". However, this cannot be done in social systems: "...organized complexity means that the character of the structures showing it depends, not only on the properties of the individual elements of which they are composed and the relative frequency with which they occur, but also on the manner in which the individual elements are connected each other." (Hayek, 1974). To make things even more complex, the people affected by these organized complexity phenomena learn, i.e., change their

\footnotetext{
${ }^{1}$ By 'formal,' they presumably mean 'methodical', 'conventional', 'organized' research, not research that is structured in logico-mathematical language. Notice that they refer exclusively to empirical research.
} 
beliefs and preferences in the process, which inevitably leads to a change in their intentions and their purposes.

5) "While in the physical sciences it is generally assumed, probably with good reason, that any important factor which determines the observed events will itself be directly observable and measurable, in the study of such complex phenomena as the market, which depend on the actions of many individuals, all the circumstances which will determine the outcome of a process, for reasons which I will explain later, will hardly ever be fully known or measurable. And while in the physical sciences the investigator will be able to measure what, on the basis of a prima facie theory, he thinks important, in the social sciences often what is treated as important happens to be accessible to measurement. This is sometimes carried to the point where it is demanded that our theories must be formulated in such terms that they refer only to measurable magnitudes" (1974). ${ }^{2}$

His arguments are even more applicable to research in the field of management. If there is a difference between management and economics, it is that management has to do with particular situations, specific people, problems of communication between people, and so on; while economics has to do with bigger aggregates and more quantitative variables.

\section{Epistemological Problems in Management}

As mentioned above, Hayek's analysis focuses on the social sciences in general, but is possibly more specifically directed towards the behavior of people in aggregate form, i.e., when 'markets' are the form of coordination of individual actions. But, as stated above, his points are even more applicable to organizations, which are the alternative form of coordinating human activity. In fact, the assumptions of economics (mainly, utility theory), extremely simplified in terms of individual motives and preferences and, thus, admittedly unrealistic from the point of view of the actual description of human behavior, are often justified from an aggregate point of view: even if all individuals do not behave exactly according to the postulates of such a theory, statistically speaking the results may be 'as if' they did. But this argument cannot be used to defend such postulates when what is at stake is one specific decision by an individual, regardless of whether that individual acts as a consumer or a producer, i.e., when we are trying to derive rules or guidelines for specific decision-making activities, which is the main objective of management theory.

A distinction established by Elster (1983) and applied to management by Ghoshal (2006) becomes quite important in this context. According to the Hayek view expressed above, the social sciences should (in general) use methods that are different from those used by the natural sciences. Hence, one might be tempted to distinguish between different kinds of science according to the specific methods of inquiry used in each one. In this view, the natural sciences employ the hypothetico-deductive method, the arts use the hermeneutic method and the social sciences rely on the dialectical method. Elster disagrees:

\footnotetext{
${ }^{2}$ At a different level, in management practice, this problem can be seen to exist in a very similar way in common expressions such as "you can only manage what you can measure" and "if you don't measure it, it won't improve".
} 
"The hypothetico-deductive method is the method for verification in all empirical sciences. If the hermeneutic method is understood as a procedure for verification, it can only be a sub-species of the hypothetico-deductive method. To be precise, the hermeneutic method is the hypothetico-deductive method applied to intentional phenomena, with some peculiar features due to the nature of these phenomena" (Elster, 1983, pp. 15-16).

According to Elster, the right distinction is the one between three modes of explanation: causal, functional, and intentional. The mode of explanation will then (partly) determine the appropriate method. "Causal explanation is the unique mode of explanation in physics, and physics is the standard instance and model of science using causal explanation. (...) Functional explanation involves such notions as benefits, adaptation, selection and evolution. (...) Biology is the paradigm for functional explanation. (...) The basic building block in the social sciences, the elementary unit of explanation is the individual action guided by some intention. (...) Intentional adaptation differs from functional in that the former can be directed to the distant future, whereas the latter is typically myopic and opportunistic" (Elster, 1983, Introduction to part 1). This view is summarized in Table 1, adapted from Elster. The two "Yes, but..." answers in the causal row for biological and social sciences have to do with the possibility of invoking causal explanations in these sciences. If we restrict ourselves to the social sciences, Elster's analysis is that they have sub-intentional and supra-intentional causal explanations. Sub-intentional causal explanations occur in "mental operations that are not governed by will or intention, but - metaphorically speaking - take place 'behind the back' of the individual concerned. Supra-intentional causality refers to the causal interaction between intentional actors" (1983, p. 20).

\section{Table 1}

\begin{tabular}{lccc}
\hline \multicolumn{1}{c}{ Mode of Explanation } & Physical Soiences & Biological Sciences & Social Soiences \\
\hline Causal & Yes & Yes, but... & Yes, but... \\
Functional & No & Yes & No \\
Intentional & No & No & Yes \\
\hline
\end{tabular}

Unfortunately, management theories at present are "overwhelmingly causal or functional in their modes of explanation" (Ghoshal, 2005). Elster (1983) goes even further and denies that functional explanations have any role in the social sciences, relating intentionality with rationality. Intentional behavior is behavior related to the future (perhaps to the long run) by individuals who are willing to sacrifice short-term satisfaction to obtain long-term results. Intentional behavior also attempts to perform actions that will result in the desired outcomes through appropriate use of available means (rationality).

All this seems to be particularly applicable to management. Management starts with an overall purpose that basically consists of gearing the organization (i.e., the people in the organization) towards doing whatever is necessary to achieve the desired results. For this purpose, organizations must 'invest' and sacrifice short-term satisfaction to obtain longterm results. Therefore, theories based on intentional explanations of behavior that by its own nature should not be short-sighted are, according to Elster's view, absolutely necessary. 
How to go about developing such theories is far from trivial. One needs a formalized language that might not be available yet, which means it has to be developed. To develop this language, it is absolutely necessary to observe reality in such a way as to capture the essential concepts and their interrelationships. Christenson (1976) indicates the methodological direction to be taken: "There are excellent grounds for believing that Newton's method - which will be called hereafter the logico-experimental method to emphasize its dual aspect - is the only method by which scientific knowledge can grow. (...) The construction of Newton's model of the Solar System simply could not have been carried out without the availability of the language of rational mechanics", but then, "a formalized language is hardly ever a theory of just one particular concrete system (such as the Solar System). It is rather a theory of a whole class of possible systems (Newtonian mechanical systems). (...) Then, the deduction from empirical observation of the contingent properties of a particular concrete system is an act of measurement on that system. (...) In short, in the logico-experimental method observational data are used only as the basis of specialization, not of generalization; they are used deductively, not inductively."

\section{Naïve Rationalism}

The formalized language needed to develop a science of management therefore has to be based on logic and mathematics. However, some mathematical models are built for problems that are not intuitively related to the real world in any realistic way, and hence are not too helpful when applied in practice. This is partly due to the use of some specific mathematics (e.g., differential calculus) that condition research, making it reductionist instead of starting to create a formalized language specifically appropriate to the problem at hand. Or, in other words, the tool sometimes conditions the formalization of the problem instead of the problem itself determining the tool to be used. Used wisely, the mathematical model may be taken to be a first approximation of the real problem; but it may become very dangerous when it is readily used for prescription.

Ghoshal provides an example of such reductionism: he states that the agency model is more widely used (at least in academic publications and in the teachings of academicians) than the stewardship theory (Davis, Schoorman and Donaldson, 1997), which is a "much more sensible proposition" because "such a perspective cannot be elegantly modeled: Math does not exist. Such a theory would not readily yield sharp, testable propositions, nor would it provide simple, reductionist prescriptions" (Ghoshal, 2005).

However, this quote by Ghoshal deserves further analysis, for it is in fact a composite of two completely different statements. One says that the math for modeling stewardship theory does not exist. This may or may not be true, but in any case, it is probably true that no one has ever attempted such a thing. The statement itself does not preclude the possibility that the math might be available in the future, or that part of this math already exists today.

The second statement is completely different and can in fact be understood to mean that more simplistic theories yield "sharp, testable propositions" and "reductionist prescriptions". But if this is true, more simplistic theories can be tested more easily than more complex ones, and 'reductionist prescriptions' can be shown to be false when they fail to achieve their goal.

These problems are related to what Christenson (1973) calls "naïve rationalism", which in short consists of the position that the "aim of a scientific theory is to 'explain' observed phenomena". As we have seen, this objective is too ambitious. In practice, this desire to explain observed 
'facts' leads to constructing mathematical models that are often very complex ways of rationalizing what has been observed. The mathematical derivation of theories constructed out of casual observations is very often a naïve rationalism of this kind. Ghoshal's critique obviously applies to this approach to research.

Donaldson (2005) interprets Ghoshal's position in a somewhat different way. According to Donaldson, Ghoshal is pessimistic about social-science research since it relies on very narrow models that are tractable for mathematical modeling. Donaldson then argues in favor of "social-science research" because (1) there is some scientific research that is not that narrow, and (2) "it is not inherent to social science that it be mathematized". It is easy to agree with the first argument: again, quite obviously, the stewardship theory developed by Davis, Schoorman and Donaldson (1997) is a good example.

But the second proposition deserves qualification. While the beginning of any science cannot by its very nature be mathematical (and, from this point of view, the beginning of the stewardship theory may be a specific case of this rule), it should ultimately be formulated in a formalized language. Therefore, whether or not a science should be mathematized should not be seen as two conceivable alternatives, but rather as different stages of development of this science. Beginnings are by necessity non-mathematical, but the end has to be 'mathematical' in the context of a formalized language.

In fact, the logico-experimental method briefly described above starts with the construction of a formalized language in logico-mathematical form, which is something completely different from the use of complex mathematics in different areas of economics and management that has so often been the subject of criticism. It is often argued (naïvely, one might add) that mathematics cannot be used to describe and predict human activities because they have an irreducible element of freedom and it is therefore impossible for mathematics to represent it adequately. This is typically based on the intuition that human behavior has elements that go beyond the familiar differential calculus used in economics, which is the tool most commonly known to many management researchers and practitioners. More in general, when someone argues against the use of mathematics in a particular discipline, it is often the case that the mathematics that this person knows is inadequate to express the observed phenomena of this discipline. Therefore, this person is to some extent right. But it might be that the mathematical tools necessary already exist, and this person is not aware of them, or that they can be developed in the future. This position has illustrious antecedents in science. Helmont, a $17^{\text {th }}$ century scientist, was very skeptical about efforts to mathematize physics and chemistry. According to him, "the rules of Mathematicks or Learning by demonstration do ill square with nature" (Mason, 1962). The mathematics of his time, before differential calculus, was indeed a poor instrument for describing continuous phenomena. But the world did not have to wait too long to have appropriate tools to deal with them: Newton and Leibnitz developed differential calculus only a few years later.

Herbert Simon's position seems to be more realistic:

"The social sciences, I thought, needed the same kind of rigor and the same mathematical underpinnings that had made the 'hard' sciences so brilliantly successful. I would prepare myself to become a mathematical social scientist. By a combination of formal training and self study, the latter continuing systematically well into the 1940s, I was able to gain a broad base of knowledge in economics and political science, together with reasonable skills in advanced mathematics, symbolic logic, and mathematical statistics. (...) I also made a serious study of graduate-level physics in order to strengthen and practice my mathematical skills and to gain 
an intimate knowledge of what a "hard" science was like, particularly on the theoretical side. An unexpected by-product of the latter study has been a lifelong interest in the philosophy of physics and several publications on the axiomatization of classical mechanics." (Simon, 1996)

As stated above, the use of logic and mathematics is just a matter of creating an internally consistent language where the possibility of inconsistencies is minimized. Once a science has developed and matured, it can and should be written in just such a language, if only to attempt to make sure it contains no contradictions. This is particularly important in management, where we want to minimize the probability of holding inconsistent beliefs or intentions or of not perceiving their logical consequences. In the end, all sciences must be structured in such an internally consistent language. The use of mathematics is therefore simply inevitable. However, this does not necessarily mean that, at a particular point in time, any given science must be in a state of development that makes this possible. This would be ridiculous. Nor does it mean that the necessary mathematics already exists: the Helmont quote anecdote above provides an example of a mathematical tool that needed to be created to be able to develop mechanics (among other parts of physics) as an axiomatic system. In the end, everything must be formal, though the road to formalization may have to be informal.

In other words, sometimes one has to start with reductionist models to be able to handle more complex situations. One way to make science advance is to relax the basic hypotheses of narrow, reductionist models so they are no longer narrow or reductionist. Alternatively, of course, one can start by developing informal models and theories. But to make them progress towards an internally consistent language, the mathematization of the theory is absolutely necessary at some point in time. What is clearly wrong and goes beyond naïveté is to assume that a reductionist model adequately represents reality, when it actually represents only a first approximation of the problem. And what is even worse is to draw prescriptions from such a reductionist model for ready application to reality. You may then end up with self-fulfilling prophecies that will change the behavior of people in a way that will make everybody worse off (Ghoshal and Moran, 1996; Ferraro, Pfeffer \& and Sutton, 2005).

Agency theory is possibly one of the best examples of these phenomena, as I will attempt to show next.

\section{Agency Theory as an Example}

It is first important to clarify in our context that there are at least two different versions of agency theory, as was early recognized by Jensen (1983). One version is the one Jensen calls the "principal-agent" literature, which appeared first in journals (Ross, 1973). This version is mathematically structured and, thus, very precise in its assumptions and rigorous in its deductions, and makes it easy for anyone to see in what direction it is possible to make progress by relaxing assumptions. The "positive" version of the theory, which appeared in the literature a few years later ( ensen and Meckling, 1976), is more informal, has more verbal and graphical analyses, and is (supposedly) more empirical. According to J ensen (1983), they both attempt to "address the contracting problem between self-interested, maximizing parties and they both use the same agency cost minimizing tautology (although not necessarily stated in that form)."

However, precisely because of the nature of these two versions, the differences between them are also substantial. Because of its precise, mathematized formulation, the "principal-agent literature" can be considered a 'first approximation' to the study of the problem of the 
hierarchical relationship, which will obviously need to be further refined by additional research, mainly by relaxing its admittedly simplistic behavioral assumptions. The "empirical" version, in contrast, which purports to be descriptive of reality, has practically the same reductionist behavioral assumptions built into the model, but its purported empiricism makes it more likely for the model to be used to draw prescriptions for practical applications when analyzing specific situations. If this happens, the danger of having self-fulfilling prophecies of the kind mentioned above is in close proximity.

In fact, both versions start (very explicitly in one case and somewhat more implicitly in the other) from the classical assumptions of economic theory that can be summarized in the concept of homo œconomicus for both the principal and the agent. Homo œconomicus is a rational being with perfect knowledge of his own tastes, and who is capable of making a decision consistent with them. These tastes are, of course, consistent themselves in the sense of not being contradictory and being transitive (i.e., if J ohn prefers $A$ to $B$ and $B$ to $C$, then he also prefers $A$ to $C$ ), but otherwise perfectly arbitrary (i.e., there is no reason why J ohn should prefer $A$ to $B$ or $B$ to $A$, except due to his own tastes).

Unbounded rationality is a crucial and often implicit assumption. If individuals can be perfectly aware of their own tastes, and hence to choose in a way that maximizes their utility, then there is no place for some common practices in the world of management such as goal-setting and persuasion, since maximizing agents will not accept anything but the best. And there will be very limited room for learning and negotiation. The only form of learning possible in a world of unbounded rationality is the Bayesian sense of updating probabilistic beliefs about uncertain variables when new information is gained. Other kinds of learning are excluded, such as an awareness of changes in agents' attitudes towards each other or of changes in their conceptions of how much they initially thought they would like the results of their actions (Rosanas, 2007).

In the standard version of agency theory, the arguments of both utility functions (the principal's and the agent's) are essentially monetary values. However, starting rather early on, some principal-agent models included disutility for effort on the part of the agent as well (i.e., an 'effort' variable of which utility is a decreasing function and 'results' an increasing function). Later, more sophisticated models attempted to include other variables, but the extent to which they achieved it within the formal model was rather limited. Variables like 'identification' and 'loyalty', which are much earlier considered in 'rational' approaches to organizations, such as that of Simon (1947), or 'caring for other people's welfare' and 'prosocial preferences' (Osterloh and Frey, 2003), are unknown in the agency literature.

Human beings interpreted as utility functions can be considered a 'mechanical' model, but at the same time, their utility represents their intentions. Thus, agency theory (like the rest of organizational economics) can be seen as an attempt to simultaneously produce Elster's 'causal' and 'intentional' explanations (Elster, 1983). In fact, unbounded rationality, paradoxically perhaps, makes human beings so intentionally calculative (taking into account the very long run as easily as the short run) that their behavior becomes perfectly foreseeable or 'mechanical' and, thus, explanations may become 'causal'. Bounded rationality makes individuals subject to different stimuli depending on specific circumstances and makes their behavior 'nonmechanical'. With unbounded rationality, the long run is anticipated just as clearly as the short run, as if everything happened in an instant. Bounded rationality, in contrast, can make causal and intentional explanations substantially different. Sacrificing something today for something else that you are going to obtain in the distant future (i.e., investing) calls for strong intentions and rationality (bounded rationality, of course). Learning about one's own real satisfaction with different outcomes, so that the investments to be made in the future are only the ones that are 
'worth' the short-run sacrifice, and learning about the whole decision-making process become crucial to explain the future behavior of rational agents.

The conventional agency models can try (partly, at least) to accommodate these types of learning and the desire for other variables by relaxing some of the initial assumptions. In fact, within the formalized framework of the principal-agent model, the developments of the last few years have gone in the direction of making assumptions more realistic from the point of view of those variables that are missing (Gibbons, 1998). There is nothing wrong with this and it may be the way to progress in science: building more realistic models where more variables are included.

The real problem is not the assumptions and the necessarily incomplete analysis, but the conclusions and the eagerness for premature practical application. If in physics we build a simplified model based on unrealistic assumptions and then keep adding more variables to make it more realistic, this does not change the behavior of the entities under study. Therefore, our model will become more and more complete. But as Ghoshal and Moran (1996) and Ferraro, Pfeffer and Sutton (2005) have shown, using models based on pessimistic assumptions about human nature to obtain recommendations for management practice may become and often do change their behavior, thus leading to a self-fulfilling prophecy for these assumptions, which then become 'realistic,' when they initially were not.

\section{Naïve Empiricism}

The next danger in management research is naïve empiricism. Naïve empiricism consists of believing that "for a statement to be scientifically meaningful, it must be logically constructible out of terms which refer to immediate experience. (...) This is sometimes expressed by saying that the atomic constituents of a scientific theory are 'fact statements.' (...) But the concept of 'fact' is a much more complex one than a naïve empiricist is willing to admit" (Christenson, 1973; see, also, Quine, 1953).

Plain, unprejudiced facts simply do not exist (Chalmers, 1976; Elster, 1983). Elster states it very clearly: "It is generally accepted that in science there is no 'theory-neutral' observation language. When engaged in deriving observational consequences from a theory to be tested, one always has to take for granted the validity of other theories that enter into the construction of the observation language. The apparently simple notion of a temperature reading embodies a vast amount of theoretical assumptions." (p. 237, note 1) Obviously, things will not be any easier in management.

Hayek (1974) warns against the use of some empirical methods:

"...what looks superficially like the most scientific procedure is often the most unscientific, and, beyond this, in these fields (the social sciences) there are definite limits to what we can expect science to achieve. (...) the confidence in the unlimited power of science is only too often based on a false belief that the scientific method consists in the application of a ready-made technique, or in imitating the form rather than the substance of scientific procedure, as if one needed only to follow some cooking recipes to solve all social problems. It sometimes almost seems as if the techniques of science were more easily learnt than the thinking that shows us what the problems are and how to approach them." 
A very common view of science is that it starts from unbiased observation of facts and then generalizes, by induction, to formulate universal laws about those facts that are generalized in subsequent steps to build theories of a more general nature. These laws and theories are then verified by comparing their empirical consequences with reality, including the initial observations. According to Mark Blaug (1980), this view (in practice identical to "naive empiricism") was the standard view of the philosophy of science in the mid-19 ${ }^{\text {th }}$ century. And yet, as early on as the end of the $18^{\text {th }}$ century, Kant and Hume had shown that this conception did not hold water; and, in the $20^{\text {th }}$ century, practically all developments in the philosophy of science, from logical positivism to Popper and from Kuhn to Lakatos, dismiss this type of approach. It is a sad fact of human nature that a point of view can survive (and not only until the mid- $19^{\text {th }}$ century, but on into the $21^{\text {st }}$, though it is less widespread) even after it has repeatedly been shown to be ill-founded.

Naïve empiricism is possibly one of the greatest dangers to the development of a science of management because it produces an army of researchers looking for aseptic 'facts' and 'empirical truths' where there are none. Empirical research obviously has an important role in the development of science, but not the one that is often believed.

After being very critical of naïve empiricism, Christenson states that there is another kind of empiricism, which he calls "sophisticated" empiricism, that is potentially very useful. A sophisticated empiricist first checks a theory for internal contradictions and contradictions with known 'facts'. Then a sophisticated empiricist tries to produce 'facts' that contradict the theory (i.e., that falsify the theory) and lets the facts decide.

In more technical words, the rationalized language that is the basis of science describes a variety of systems that are logically possible. In the context of such a language, empirical observations attempt to determine which conceivable system we are observing. This is the role of empirical research (Christenson, 1976).

\section{Falsification and Common Sense in Management Theory}

Falsification is thus a crucial concept. And it has already been argued that the hypotheticodeductive method is the only method for theory verification in all the empirical sciences. It essentially consists of developing a set of logically consistent, universal, falsifiable (i.e., that can empirically be proven false) statements and their logical consequences, and then to look for facts that contradict (i.e., falsify) such a theory. A statement that is falsifiable and has not been falsified after some serious attempts to do so is then accepted as scientific. This is always provisional, since new facts might appear to falsify it. This demarcation principle (i.e., the principle that separates the scientific from the unscientific) originates in the writings of Karl Popper and is widely accepted today by philosophers of science ${ }^{3}$. But it is sometimes seen as if it were a straitjacket on the social sciences, when in fact it is not.

Ghoshal, for instance (2005), on the one hand begins his paper by accepting the "common view" that considers "management-related theories as part of the social science", and then carefully analyzes Elster's distinction between the three types of explanation (causal, functional

\footnotetext{
${ }^{3}$ Incidentally, Popper's falsification criterion is a significant departure from the verificationist position of logical positivism, one of the two basic tenets of that school (the other one being logical analysis). Logical positivism demands verification of a given proposition as a criterion for considering it scientific, while Popper proposes only falsifiability (i.e., the possibility of an experiment proving the statement wrong), essentially because in his view (which is now widely accepted), verification of positive, universal propositions is logically impossible.
} 
and intentional) and strongly argues (with Elster) that the social sciences basically have to rely on intentional explanations. This is hardly disputable, although it is inconsistent with a vast proportion of today's management research, which at best shoots for functional explanations. But on the other, Ghoshal makes strong statements that may not be altogether compatible with this initial view. He states that,

"Scholarship of common sense is the epistemology of disciplined imagination as advocated by Karl Weick (1989), and not the epistemology of formalized falsification that was the doctrine of Karl Popper (1968)" (p. 81).

He provides no reason for making this statement or for arguing that "common sense" and "falsification" are mutually incompatible. "Disciplined imagination" is probably a very good basis for "theory construction", which is the basic point of Weick's article (as suggested by its title), but this is by no means in contradiction with falsification, which is a part of the hypothetico-deductive model and thus a much better basis for theory verification (indeed, as we have seen, it is the only one according to both Popper and Elster). Thus, disciplined imagination and falsification can be seen as complements rather than competitors.

Later on, Ghoshal states that,

"...the trouble in the social sciences is that the logic of falsification, which is so very essential for the epistemology of positivism, is very hard to apply with any degree of rigor and ruthlessness in the domain of social theories. Typically, no theory - which are all, by definition, partial - explains a 'phenomenon of organized complexity' fully, and many different and mutually inconsistent theories explain the same phenomenon, often to very similar extents" (p. 86).

The second part of the above quote is true, but the first part is an often-defended position without foundation. Theories are by definition partial and none can "fully explain" any kind of phenomena. As stated above, explanation is in general too ambitious an aspiration for a theory. But in the logic of Popper, a statement or a whole set of logically interconnected statements can have scientific status even if they are not falsifiable, provided there exist some logical consequences of these statements that are falsifiable. This is, indeed, a very reasonable demand. When a statement cannot be falsified and its logical consequences cannot be falsified either, it may be a very respectable belief, but it is difficult to grant it scientific status. The complexity of the problem is irrelevant to that purpose. In fact, there is no reason why falsification should be more difficult to apply in the social sciences than it is in the natural sciences. It is true that all theories are, by definition, partial, but the possible fear that the straightforward application of falsification will prove all theories "wrong" or "false" is just as justified in the social sciences as in the natural sciences. Surely, "organized complexity" does not make things any easier, but there is no reason to believe it makes them impossible. In both the social and the natural sciences there are always competing, incompatible theories that explain the same phenomena and there is nothing wrong with that. The Ptolemaic theory of astronomy, for instance, explained everything that happened in the sky very well, just as the Copernican-Galilean-Newtonian theory does, and they are incompatible. The latter is much simpler, easier to understand and use, and does not call for ad-hoc explanations for any new phenomena observed, which are the basic reasons it came to be accepted as a 'better' explanation. Incidentally, the Copernican-Galilean-Newtonian theory does not provide a very good explanation of the phenomena observed when masses reach speeds close to the speed of light; the theory of relativity is needed in such cases. Newtonian 
mechanics and the theory of relativity coexist in any good physics and engineering curriculum, even though the latter proves the former 'false'. But it is an approximation that is good enough for most practical purposes (including sending rockets to the moon).

Donaldson (2005) disagrees with Ghoshal when he argues for "common sense" as the basis of science. He rightly provides an example of how historically, even in the hard sciences, progress has often meant a fight against the "common-sense view", which sometimes cannot go beyond very simple, intuitive ideas that seem to be "right" but are not. J ust to stress this point, it is clear that the model that has been (and possibly still is) the most successful in history, i.e., Newtonian mechanics, is based on three "axioms"4 or principles that are counterintuitive to the layman; and yet the concepts of Aristotelian physics that it replaced are full of "common sense". There resides, perhaps, the greatest part of Newton's credit. Using "common sense" as the only criterion would have meant dismissing the most successful model in the history of science as "unscientific".

Of course, all this does not mean that common sense should play no role in the social sciences, or that there is no common sense in research. For one thing, many of the traps discussed in this article are fairly obvious with a little bit of common sense. But researchers sometimes get carried away with their standard methods and forget about the basic nature of the problem. In any case, the role played by common sense cannot be reduced to that. In all sciences, common sense must play a role that comes before (and, at the same time, goes beyond) strict model-building. Good theory grows out of practice (Christenson, 1973; 1976) and good practice is not possible without common sense. Christenson quotes Pareto (1935) and says that "the dyer's art was more safely entrusted to the dyer who knew his trade by rule of thumb than to alchemists who played with the theoretical lucubrations of magic and other such nonsense".

In other words, dyers were quite successful in their trade in the Middle Ages because they used their experience and common sense, and this put them far ahead of chemistry, which was in its pre-scientific stage of alchemy. It has only been through the interaction of good practice and scientific development that good theories have grown.

\section{Naïve Pragmatism}

A very serious consequence of the two forms of "naïveté" briefly described above is that both practitioners and practical-minded academicians, disappointed with the pretended scientific rigor of something they do not understand and that does not offer guarantees that it works (unrealistic formal models that aim to describe reality, alleged empirical evidence that is in fact worse than a half-truth), turn to knowledge coming directly from practice (or common sense) without the necessary guarantees that could make this knowledge solidly founded and really useful. And academicians complain about practitioners do not use what they have to offer. The controversies in the articles cited above (i.e., Van de Ven and Johnson, 2006; McKelvey, 2006) go along these lines. This is a third type of "naïveté": naïve pragmatism. According to Christenson (1973), naïve pragmatism is the idea that scientific knowledge should be immediately 'useful', possibly coming directly from experience, and "therefore the sooner it is used, the better". The 'common-sense idea' that experience, directly and without further reflection, provides 'facts' on which one can base practical knowledge is at the same time naïve pragmatism

\footnotetext{
${ }^{4}$ Principle of inertia, principle of action and reaction, and $f=m . a, m$ being a constant independent of $v$.
} 
and naïve empiricism. A theoretical structure is needed to avoid falling into that double trap. That is unfortunately what happens in many of the best-selling books on management, which are typically written by non-academicians looking for direct recipes based on so-called 'facts'.

As the usual argument goes, they choose 'relevance' as opposed to 'rigor'. The contrast between the two concepts is in itself absurd: knowledge that is not 'rigorous' can never be 'relevant'. Rigor is only the minimum assurance that the knowledge is genuine, coming from experience, but with guarantees (a theoretical structure and some conditions on the observation process) that it is not fake knowledge or superstition. If we have no solid basis to declare that some knowledge is 'true', then this knowledge is extremely dangerous, no matter how successful some applications of it have been. A little knowledge is always a dangerous thing. Unfortunately again, the 'rigor' that is often challenged as being the cause of irrelevance, instead of 'rigor,' is in fact adherence to specific research methods that, to paraphrase the Hayek quote above, are decidedly unscientific in the true sense of the word.

To illustrate this point further, it is good idea to remember what Galileo Galilei (1665) had to say about his observations at the Arsenal of Venice. In his "Dialog Concerning Two New Sciences", the character that represents Galileo himself (Salviati) and the intelligent layman accompanying him (Sagredo), discuss how interesting it was to go to the Venice Arsenal "for the mere pleasure of observing the work of those who, on account of their superiority over other artisans, are called first-rank men." He thought that the instruments and machines being constructed there were so good that "there must be some (artisans) who, partly by inherited experience and partly by their own observations, have become highly expert and clever in explanation". But sometimes, when they are asked questions about why they do something, the reason they give is not a good one (e.g., the reasons for employing stock, scaffolding and bracing of proportionally larger dimensions for launching big vessels than for launching smaller ones). "The common opinion is here absolutely wrong," says Salviati. In other words, Galileo shows (rightly, we know today) that the artisans in fact did the right thing (otherwise, one might add, the vessel would not have worked), but they were doing it for the wrong reason. Their 'common sense', acquired through their own and inherited experience, allowed them to do what was right, but did not tell them the real reason behind their practice (Galilei, 1665, First Day). Finding the right 'whys' is the role of the academician, but this has to be done in contact with good practice, not against it.

Admittedly, in the social sciences in general and in management in particular, everything is more complex than in the natural sciences because (i) it is more difficult to recognize when a practice 'works' and when it does not, and (ii) it is more difficult to know exactly what is desired as a result (e.g., shareholder-value maximization or broader goals). In fact, these are the main problems with the so-called 'evidence-based management' approach: knowing when something works or not, and knowing when the results are good or bad. And that is why a methodological reflection and debate on what we are doing today in management research is indispensable. 


\section{Summary and Conclusions}

There are all kinds of methodological problems in the social sciences in general, and in management in particular. These problems have been overlooked for a number of years, but now seem to have sparked people's interest. Unfortunately, there is a wide gap between the philosophy of science and management, where scholars in the two fields are often incapable of understanding each other. The issues raised by Ghoshal (2005), Rousseau (2006), Smith and Hitt (2005) and others should be the starting point of a better understanding of the methodological issues and a review of the accepted research methods in light of sound methodology.

The main objective of this paper is to contribute towards applying the essential concepts of the philosophy of science to management. To do so, I started by trying to distinguish between a sound concept of science and the intuitive, simplistic view of it as applied to management, which often consists of scientism rather than science. Then I examined some epistemological problems in economics (which is often taken today as the paradigm of social science) and, from there, the epistemological problems of a science of management. The role of mathematics and formal models were discussed, and the naïve, extreme views of rationalism, empiricism and pragmatism analyzed. Finally, I discussed the role of common sense and practice in the growth of a sound theory of management. 


\section{References}

Blaug, M. (1980), "The M ethodology of Economics," Cambridge University Press, 1980.

Chalmers, A.F. (1976), "What is this thing called Science?: An Assessment of the Nature and Status of Science and its Methods," University of Queensland Press, St. Lucia, Queensland.

Christenson, Ch. (1973), "The "Contingency Theory" of Organization: a Methodological Analysis," Working Paper HBS 73-36, Harvard Business School, Boston, Massachusetts.

Christenson, Ch. (1976), "Proposals for a Program of Empirical Research into the Properties of Triangles," Decision Sciences, 7, pp. 631-648.

Christenson, Ch. (1983), "The Methodology of Positive Accounting," The Accounting Review, LVIII (1), pp. 1-22.

Davis, J.H., F.D. Schoorman, and L. Donaldson (1997), "Toward a stewardship theory of management," A cademy of Management Review, 22, pp. 20-47.

Donaldson, L. (2005), "For Positive Management Theories While Retaining Science: Reply to Ghoshal," A cademy of Management Learning \& Education. 4 (1), pp. 109-113.

Eccles, R. and N. Nohria, (1992), "Beyond the Hype: Rediscovering the Essence of Management," Harvard Business School Press, Boston.

Einstein, A. (1956), "The meaning of relativity," Princeton University Press, Princeton, NJ .

Elster, J. (1983), “Explaining Technical Change," Cambridge University Press, Cambridge, England.

Ferraro, F., J. Pfeffer, and R. Sutton, (2005), "Economics Language and Assumptions: How Theories May Become Self-Fulfilling," A cademy of Management Review, 30 (1), pp. 8-24.

Follet, M.P. (1927), "Management as a profession", In H. Metcalf, "Business Management as a Profession," pp. 73-87, McGraw-Hill Co. New York. (Reprinted as Chapter 2 in Matteson, M. and J. Ivancevich (1986), "Management Classics," Third Edition, pp. 7-17, Business Publications, Plano, Texas.

Galilei, G. (1665) (English version, 1954), "Discorsi e dimostrazioni matematiche intorno à due nuoue Scienze (Dialogues Concerning Two New Sciences)," English version, Dover Publications, New York

Ghoshal, S. (2005), "Bad Management Theories are Destroying Good Management Practices," A cademy of Management Learning \& Education, 4 (1), pp. 75-91.

Ghoshal, S. and P. Moran (1996), "Bad for Practice: A Critique of Transaction Cost Theory," A cademy of Management Review. 21 (1), pp. 13-47.

Gibbons, R. (1998), "Incentives in Organizations," J ournal of Economic Perspectives, 12 (4), pp. 115- 132.

Gulick, L. (1965), “Management is a Science," A cademy of Management, M arch. 
Hayek, F.A. (1952), "The Counter-Revolution of Science," The Free Press, Glencoe, III.

Hayek, F.A. (1974), "The pretence of knowledge," Nobel Lecture, The Nobel Foundation. Reprinted in American Economic Review, 79 (6), pp. 3-7.

J ensen, M. (1983), "Organization Theory and Methodology," The Accounting Review, LVIII (2), pp. 319-339.

Jensen, M. and B. Meckling, (1976), "Theory of the Firm: Managerial Behavior, Agency Costs and Ownership Structure," J ournal of Financial Economics, 3, pp. 305-360.

Learmonth, M. (2006), "Is There Such a Thing as "Evidence-Based Management": A Commentary on Rousseau's 2005 Presidential Address," Academy of Management Review, 31 (4), pp. 1089-1093.

Mason, S. (1962), "A History of the Sciences" (new revised edition), Collier Books, The MacMillan Company, New York.

McKelvey, B. (2006), Van de Ven and Johnson's "Engaged Scholarship": Nice Try, but... A cademy of Management Review, 31 (4), pp. 822-829.

Osterloh, M. and B. Frey, (2003), "Corporate Governance for Crooks? The Case for Corporate Virtue," Working paper ISSN 1424-0459, Institute for Empirical Research in Economics, University of Zurich.

Pareto, W. (1935), "The mind and society" (English translation), Dover, New York.

Quine, W. (1953), "Two dogmas of empiricism," In Quine, W., ed., "From a logical point of view," Harvard University Press, Cambridge, Massachusetts.

Rosanas, J. (2007), "Beyond Economic Criteria: A Humanistic Approach To Organizational Survival," J ournal of Business Ethics. DOl 10.1007/s10551-006-9341-9.

Ross, S. (1973), "The Economic Theory of Agency: the Principal's Problem," American Economic Review, 63 (5), pp. 134-139.

Rousseau, D. (2006), "Is There Such Thing as "Evidence-Based Management"?," A cademy of Management Review, 31 (2), pp. 256-269.

Simon, H.A. (1996), "Models of my life," Massachusetts Institute of Technology Press, Cambridge, Mass.

Smith, K.G., and M.A., Hitt, editors (2005), "Great Minds in Management. The Process of Theory Development," Oxford University Press, Oxford.

Van de Ven, A. and P. Johnson, (2006), "Knowledge for Theory and Practice," Academy of Management Review, 31 (4), pp. 802-821.

Weick, K. E. (1989), "Theory construction as disciplined imagination," A cademy of Management Review, 14, pp. 516-531. 